Article

\title{
Determine Cumulative Radiation Dose and Lifetime Cancer Risk in Marfan Syndrome Patients Who Underwent Computed Tomography Angiography of the Aorta in Northeast Thailand: A 5-Year Retrospective Cohort Study
}

\author{
Narumol Chaosuwannakit ${ }^{1}$ * , Phatraporn Aupongkaroon ${ }^{1}$ and Pattarapong Makarawate ${ }^{2}$ \\ 1 Radiology Department, Faculty of Medicine, Khon Kaen University, Khon Kaen 40000, Thailand; \\ phatraaupong@gmail.com \\ 2 Cardiology Unit, Internal Medicine Department, Faculty of Medicine, Khon Kaen University, \\ Khon Kaen 40000, Thailand; nchaosuw@gmail.com \\ * Correspondence: narumol_chao@yahoo.com
}

Citation: Chaosuwannakit, N.; Aupongkaroon, P.; Makarawate, P. Determine Cumulative Radiation Dose and Lifetime Cancer Risk in Marfan Syndrome Patients Who Underwent Computed Tomography Angiography of the Aorta in Northeast Thailand: A 5-Year Retrospective Cohort Study. Tomography 2022, 8, 120-130. https://doi.org/10.3390/ tomography 8010010

Received: 26 November 2021

Accepted: 2 January 2022

Published: 5 January 2022

Publisher's Note: MDPI stays neutral with regard to jurisdictional claims in published maps and institutional affiliations.

Copyright: (C) 2022 by the authors. Licensee MDPI, Basel, Switzerland. This article is an open access article distributed under the terms and conditions of the Creative Commons Attribution (CC BY) license (https:// creativecommons.org/licenses/by/ $4.0 /)$.

\begin{abstract}
Objective: To evaluate computed tomography angiography (CTA) data focusing on radiation dose parameters in Thais with Marfan syndrome (MFS) and estimate the distribution of cumulative radiation exposure from CTA surveillance and the risk of cancers. Methods: Between 1st January 2015 and 31st December 2020, we retrospectively evaluated the cumulative CTA radiation doses of MFS patients who underwent CTA at Khon Kaen University Hospital, a leading teaching hospital and advanced tertiary care institution in northeastern Thailand. We utilized the Radiation Risk Assessment Tool (RadRAT) established at the National Cancer Institute in Bethesda, Maryland, to evaluate the risk of cancer-related CTA radiation. Results: The study recruited 29 adult MFS patients who had CTA of the aorta during a 5-year study period with 89 CTA studies. The mean cumulative CTDI vol is $21.5 \pm 14.68 \mathrm{mGy}$, mean cumulative DLP is $682.2 \pm 466.7 \mathrm{mGy} . \mathrm{cm}$, the mean baseline future risk for all cancer is $26,134 \pm 7601$ per 100,000 , and the excess lifetime risk for all cancer is $2080.3 \pm 1330$ per 100,000 . The excess lifetime risk of radiation-induced cancer associated with the CTA surveillance study is significantly lower than the risk of aortic dissection or rupture and lower than the baseline future cancer risk. Conclusions: We attempted to quantify the radiation-induced cancer risk from CTA surveillance imaging performed for MFS patients in this study, with all patients receiving a low-risk cumulative radiation dose (less than $1 \mathrm{~Gy}$ ) and all patients having a low excessive lifetime risk of cancer as a result of CTA. The risk-benefit decision must be made at the point of care, and it entails balancing the benefits of surveillance imaging in anticipating rupture and providing practical, safe treatment, therefore avoiding morbidity and mortality.
\end{abstract}

Keywords: Marfan syndrome; CTA; radiation dose; lifetime cancer risk; CTA aorta

\section{Introduction}

Marfan syndrome (MFS) is a connective tissue disorder that affects the ocular, musculoskeletal, and cardiovascular systems. The majority of patients would suffer from their aortic root pathology, which would manifest as either a fatal aortic aneurysm rupture or dissection complications [1-3]. Since preventive surgery can prevent aortic dissection and rupture, early detection and diagnosis are essential [2,3]. Patients with MFS now receive multidisciplinary management with more frequent surveillance and early preventative surgery, which has resulted in increased lifespan and decreased emergency surgeries. Over the last three decades, prestigious scientific medical centers have pioneered modern MFS care, including preventing and treating life-threatening cardiovascular complications [4-7]. Aortic enlargement is typically the largest at the sinuses of Valsalva in MFS, which causes annuloaortic ectasia (Figure 1). This pattern can also be noticed in individuals who may not 
have the Marfan phenotype [1-3]. Once aortic dilatation is indicated based on echocardiography, a computed tomography angiography (CTA) or magnetic resonance imaging (MRI) is performed to establish the diagnosis and determine management decisions for aortic aneurysms. This is exceptionally crucial when diameters are on the borderline to determine whether or not to proceed with intervention and monitor enlargement rates during followup to ensure that the entire aorta is visualized and the affected regions are identified [6-8]. Diagnostic follow-up utilizing MRI or CTA at periodic intervals is recommended for MFS patients treated without surgical or endovascular intervention, according to the European Society of Cardiology (ESC) guidelines on the diagnosis and management of aortic diseases [9]. Since echocardiography does not allow for the visualization of the whole thoracic aorta, a periodic MRI or CTA, as appropriate, is required. On a patient-by-patient basis, however, the rate of development and the risk of dissection is unpredictable [8-10]. Because of its availability, rapidity, and excellent spatial resolution, CTAs have been performed and recommended for serial follow-up of MFS patients (Figure 1) [8-11].

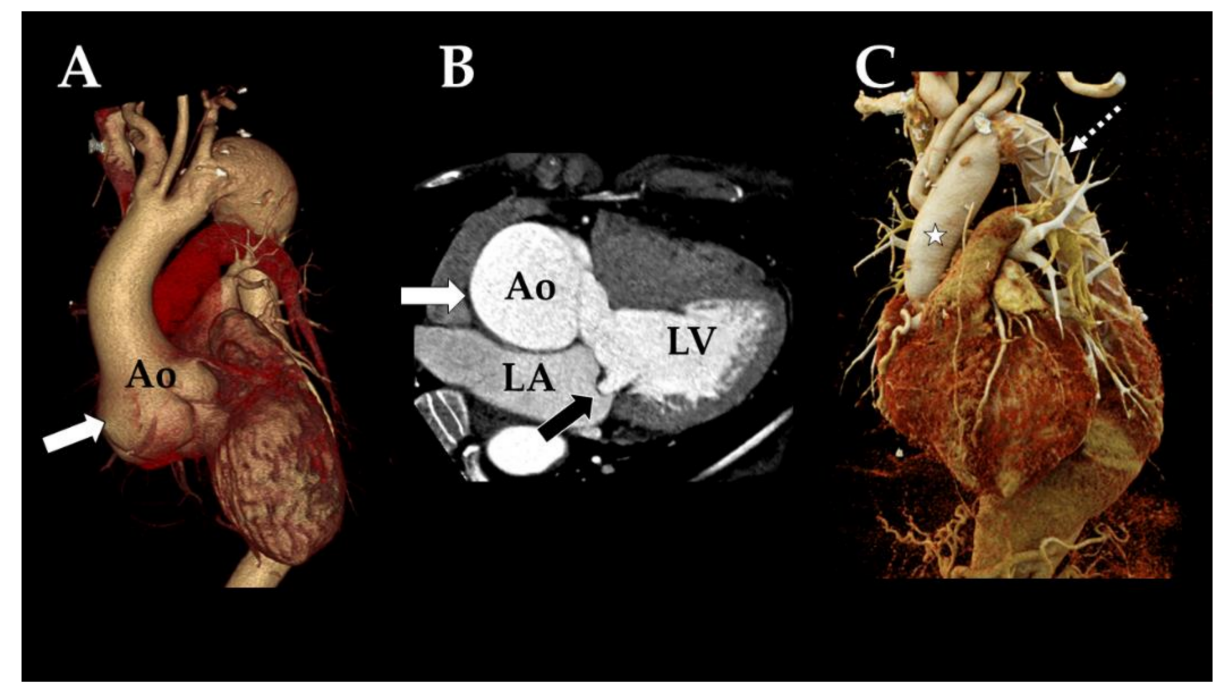

Figure 1. Thoracic aorta CTA findings in Marfan syndrome patients: The 3D volume rendering technique image (A) and three-chamber view image (B) showed dilated aortic root in tulip bulb configuration and annuloaortic ectasia (white arrow). Mitral valve prolapse is demonstrated (B: black arrow). The post-operative CTA image demonstrated the normal size of the vascular graft at ascending thoracic aorta (C: star) and evidence of thoracic endovascular aortic repair (C: dashed arrow). (Ao; aorta, LA; left atrium, LV; left ventricle).

Patients with MFS are subjected to repeated CTAs of the aorta, resulting in substantial lifetime radiation doses. Several studies on MFS's clinical outcomes and CTA data have been published, even though they are primarily from Western populations [8-10]. Moreover, no CTA data regarding Thai MFS patients have ever been reported. The purpose of this study was to assess the CTA data with a focus on radiation dose parameters of Thai individuals with Marfan syndrome, and to estimate the distribution of cumulative radiation dose from CTA surveillance and associated lung and all organ cancer risk.

\section{Materials and Methods}

\subsection{Patient Population}

We retrospectively reviewed the accumulative CT radiation doses of MFS patients who underwent CTA at Khon Kaen University Hospital, the principal teaching hospital and advanced tertiary care institution in northeastern Thailand, between 1st January 2015 and 31st December 2020. Patient identification was made by reviewing our institution's picture archiving and communication system (PACS) records data. The local Ethics Committee of Khon Kaen University, Thailand, reviewed and approved this study and was registered 
under reference number HE641421. The study was conducted according to the Declaration of Helsinki principles. All methods were performed in accordance with the relevant guidelines and regulations. The local Ethics Committee of Khon Kaen University also approved our investigation with a waiver of informed consent due to retrospective study design, and patient confidentiality was protected. Cardiologists and ophthalmologists perform a comprehensive physical examination, particularly in the ocular, cardiovascular, and musculoskeletal systems, giving MFS patients a definite diagnosis. The revised Ghent's nosology for Marfan syndrome has been used to establish the MFS diagnosis [2]. A diagnosis of definite MFS requires at least two systems with major criteria and one additional system involvement, either major or minor. We identified all MFS adult patients (age $>15$ years) who underwent one or more CT scans, including at least two cancer-sensitive tissue organs or areas (brain, neck, spine, chest, abdomen, and pelvis). The exclusion criteria were the missing radiation dose data in the PACS, $>80$ years of age, or death during or after the hospital admission (Figure 2).

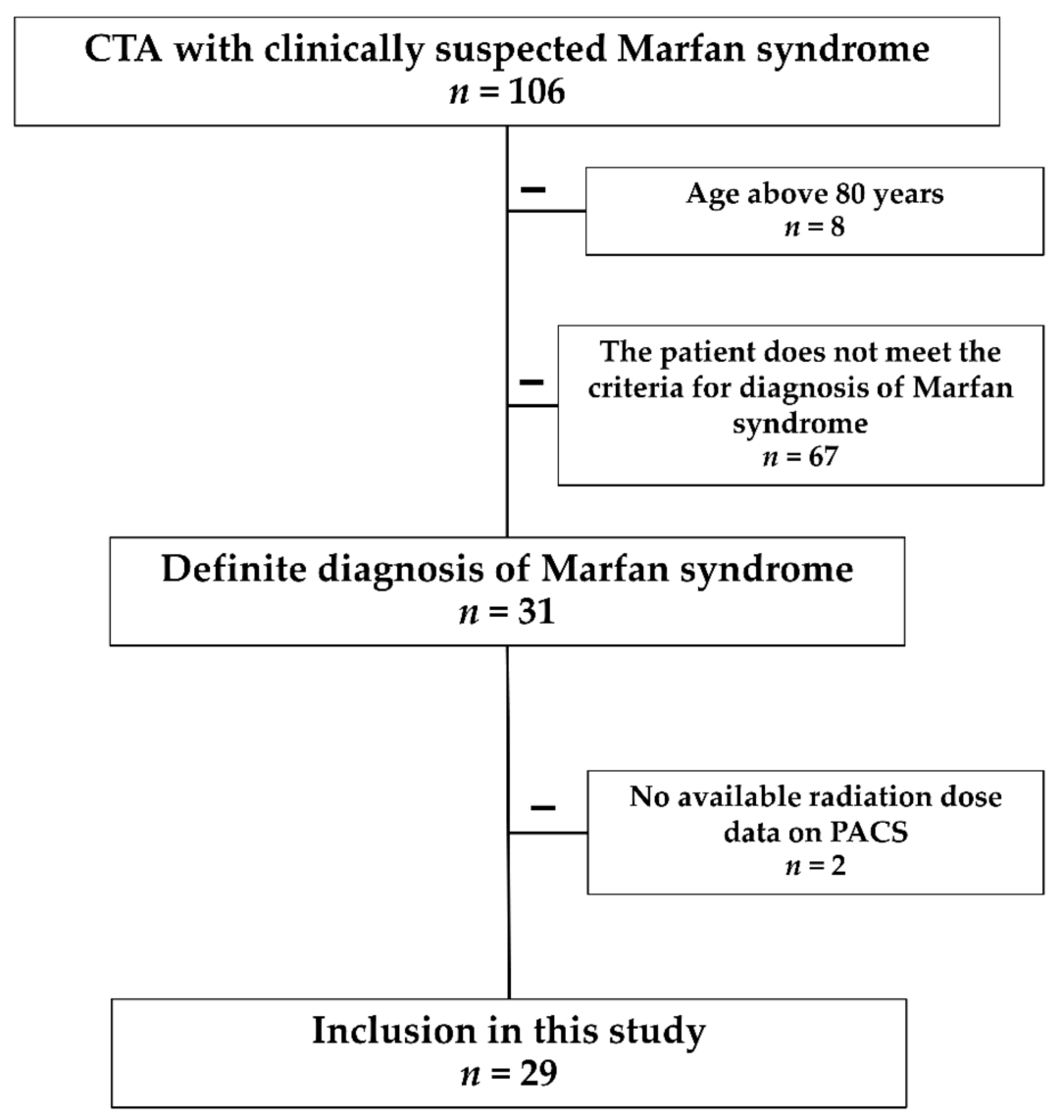

Figure 2. Flowchart for the patients' inclusion and exclusion in the study.

\subsection{Computed Tomography Angiography (CTA)}

We had three CT scanners during the study period: a 128-slice Optima CT 660 (GE Healthcare, North Richland Hills, TX, USA), a Brilliance iCT scan 128 (Philips Healthcare, Amsterdam, The Netherlands), and a dual-source Somatom definition Flash (Siemens Healthineers, Forchheim, Germany). Standard protocol for CTA aorta was performed on all studies.

\subsection{Definition and Dosimetry}

The computed tomography dose index volume $\left(\mathrm{CTDI}_{\mathrm{vol}}\right)$ was provided for a $32 \mathrm{~cm}$ CTDI phantom. The $\mathrm{CTDI}_{\mathrm{vol}}$ is dependent on the imaging acquisition and the exposure 
parameters input such as the peak kilovoltage $(\mathrm{kVp})$, the product of current and exposure time (mAs), bundle filtering, collimation, and pitch. The $\mathrm{CTDI}_{\mathrm{vol}}$ and dose length product (DLP) were recorded for each CT examination. The patient dose data, $\mathrm{CTDI}_{\mathrm{vol}}$, and DLP) values were extracted from the picture archiving and communication system (PACS). A summary of the two relevant dose parameters is given below, along with methods for calculating these factors. The Dose Length Product (DLP, units: mGy.cm) indicates the mean absorbed dose to the patient of each sequence in a CT exam and is calculated by multiplying $\mathrm{CTDI}_{\mathrm{vol}}$ by the scan length. It measures the total CT examination's mean effective dose to the patient $[12,13]$. The CT monitor's real-time CTDI $_{\mathrm{vol}}$ and DLP displays were collected in the PACS and retrospectively analyzed.

\subsection{Estimated Lifetime Cancer Risk}

The Radiation Risk Assessment Tool (RadRAT), developed at the National Cancer Institute in Bethesda, MD, and available at https://radiationcalculators.cancer.gov/radrat/ (accessed on 1 October 2021), was used to estimate the risk of cancer-associated by CTA radiation [14]. The Radiation Risk Assessment tool (RadRAT) was developed primarily utilizing data from survivors of the Hiroshima and Nagasaki atomic explosions and patients receiving radiation from the Biological Effects of Ionizing Radiation (BEIR) VII report [14]. The following information is necessary to estimate the cancer risk, as indicated on the RadRAT workflow: Patient's sex and year of birth, number of exposures, exposure event, year of each exposure, exposed regions (organ), exposure rate (chronic or acute), and exposure dose distribution with related characteristics are all part of the exposure history. The lifetime risk estimates calculator was created using the Analytica programming software and Monte Carlo simulation methods using Latin hypercube sampling to predict a distribution of potential lifetime risk estimates. Gonzalez et al. described the methodology, and statistical calculations used to estimate the risk of radiation-induced cancer [14].

\subsection{Statistical Analysis}

Continuous data were expressed as mean $\pm \mathrm{SD}$. A significance level of $p<0.05$ was considered a statistically significant result, and all reported $p$-values were two-sided. Means were compared using unpaired $t$-test, and Mann-Whitney rank sum was used when data were not normally distributed. All the patient's demographics are based on their initial scan. According to Kolmogorov-Smirnov tests, the distributions of cumulative CTDI ${ }_{\mathrm{vol}}$, cumulative DLP, and the excess lifetime risk for cancer were not substantially different from normal. Hence, they are provided as mean and SD. The correlation between different variables was determined using Pearson's correlation equation. The difference between the two data sets was assessed using repeated analysis of variance (ANOVA) with GreenhouseGeisser. The Rank-sum test compared different parameters, lifetime attributable risk (LAR) cancer incidence, and cumulative effective doses between emergency surgery and elective surgery patients. The lifetime risk of developing cancer of the ionizing radiation (chances in $100,000)$ between baseline future risk and excessive lifetime risk to the end of the expected lifetime were compared using Fisher's exact test.

\section{Results}

The study recruited 29 adult MFS patients who had CTA of the aorta during a 5-year study period with 89 CTA studies. The demographic data, clinical features, and outcomes of MFS patients are demonstrated in Table 1. The mean age at diagnosis is 31.1 years. The operative and radiation dose information is shown in Table 2. There is no statistically significant between the patients who underwent emergency surgery and elective surgery of age, gender, weight, height, body mass index (BMI), and underlying hypertension. The most frequent cause for emergency surgery is aortic dissection with Stanford type A $(n=6)$, followed by complicated aortic dissection, Stanford type B $(n=2)$, and aortic rupture $(n=1)$. The emergency surgery group underwent repeat operation and CTA more frequently than the elective surgery group ( $p=0.01$ and $p=0.04$, respectively). The cumulative CT radiation 
exposure of each patient was determined, and the biological effects of the ionizing radiation approach were used to estimate the lifetime risk of cancer. The emergency surgery group had significantly higher cumulative $\mathrm{CTDI}_{\mathrm{vol}}$, DLP, excessive lifetime risk for all cancer, and excessive lifetime risk for lung cancer. The baseline future risk for all cancers is not statistically significant between the emergency surgery and elective surgery groups (Table 2). Summary data for CTA counts, radiation dose, the excess lifetime risk of all cancer, excessive lifetime risk for lung cancer, the baseline future risk for all cancer, and the total future risk (per 100,000) are shown in Table 3. The cumulative DLP and CTDI $\mathrm{vol}_{\mathrm{v}}$ for each individual are shown in Figures 3 and 4, respectively. The mean cumulative $\mathrm{CTDI}_{\mathrm{vol}}$ is $21.5 \pm 14.68 \mathrm{mGy}$, mean cumulative DLP is $682.2 \pm 466.7 \mathrm{mGy} . \mathrm{cm}$, the mean baseline future risk for all cancer is $26,134 \pm 7601$ per 100,000, and the excessive lifetime risk for all cancer is $2080.3 \pm 1330$ per 100,000 radiation doses. The excessive lifetime risk of radiation-induced cancer associated with the CTA surveillance study is significantly lower than the baseline future risk of cancer and lower than the risk of aortic dissection or rupture $(p<0.0001)$ (Figure 5).

Table 1. Patient demographics, clinical features, and outcomes of patients with Marfan syndrome.

\begin{tabular}{cc}
\hline \multicolumn{2}{c}{ Features } \\
\hline Age at diagnosis (years), mean \pm SD & $31.1 \pm 9.4$ \\
\hline Male, $n(\%)$ & $13(44.8)$ \\
\hline Weight $(\mathrm{kg})$, mean $\pm \mathrm{SD}$ & $60.9 \pm 10.2$ \\
\hline Height $(\mathrm{cm})$, mean $\pm \mathrm{SD}$ & $171.9 \pm 6.8$ \\
\hline BMI $(\mathrm{kg} / \mathrm{m} 2)$, mean $\pm \mathrm{SD}$ & $20.4 \pm 2.3$ \\
\hline Family history of Marfan syndrome & $10(34.5)$ \\
\hline No surgery, $n$ (\%) & $3(10.3)$ \\
\hline Post-operative follow-up (years), mean $\pm \mathrm{SD}$ & $1.8 \pm 1.1$ \\
\hline HT, $n(\%)$ & $5.1 \pm 2.2$ \\
\hline Smoking, $n(\%)$ & $5(17.2)$ \\
\hline
\end{tabular}

$\overline{\mathrm{SD}}$, standard deviation; BMI, body mass index; HT, hypertension.

Table 2. Patient demographic data, operative, and radiation dose information, the excessive lifetime risk of all cancer, excessive lifetime risk for lung cancer, the baseline future risk for all cancer, and the total future risk (per 100,000).

\begin{tabular}{|c|c|c|c|}
\hline Feature & $\begin{array}{c}\text { Emergency Surgery } \\
n=9\end{array}$ & $\begin{array}{c}\text { Elective Surgery } \\
n=20\end{array}$ & $\begin{array}{l}p \text {-Value } \\
(95 \% \text { CI })\end{array}$ \\
\hline Age (years), mean $\pm S D$ & $35.8 \pm 7.3$ & $29.1 \pm 9.7$ & $0.07(-14.16$ to 0.76$)$ \\
\hline Male, $n(\%)$ & $4(44.4)$ & $9(45)$ & $0.97(-34.09$ to 33.54$)$ \\
\hline Weight $(\mathrm{kg})$, mean $\pm \mathrm{SD}$ & $62.4 \pm 10.0$ & $60.3 \pm 10.5$ & $0.62(-10.63$ to 6.42$)$ \\
\hline Height $(\mathrm{cm})$, mean \pm SD & $172.1 \pm 5.9$ & $171.8 \pm 7.3$ & $0.91(-5.99$ to 5.39$)$ \\
\hline $\mathrm{BMI}(\mathrm{kg} / \mathrm{m} 2)$, mean $\pm \mathrm{SD}$ & $20.9 \pm 2.1$ & $20.1 \pm 2.3$ & $0.38(-2.64$ to 1.05$)$ \\
\hline
\end{tabular}


Table 2. Cont.

\begin{tabular}{|c|c|c|c|}
\hline Feature & $\begin{array}{l}\text { Emergency Surgery } \\
\qquad n=9\end{array}$ & $\begin{array}{l}\text { Elective Surgery } \\
\qquad n=20\end{array}$ & $\begin{array}{l}p \text {-Value } \\
(95 \% \mathrm{CI})\end{array}$ \\
\hline $\begin{array}{c}\text { Aortic dissection } \\
\text { Stanford type A, } n(\%)\end{array}$ & $6(66.7)$ & $0(0)$ & 0.0001 (31.5 to 87.96$)$ \\
\hline $\begin{array}{l}\text { Aortic dissection, Complicated Stanford type } \\
\qquad \mathrm{B}, n(\%)\end{array}$ & $2(22.2)$ & $2(10)$ & $0.38(-13.4$ to 45.51$)$ \\
\hline Aortic rupture, $n(\%)$ & $1(11.1)$ & $0(0)$ & $0.13(-7.4$ to 43.5$)$ \\
\hline Rapid growth (>10 mm/y), n (\%) & $0(0)$ & $2(10)$ & $0.33(-20.8$ to 30.1$)$ \\
\hline Family history of Marfan syndrome, $n(\%)$ & $1(11.1)$ & $2(10)$ & $0.93(-20.9$ to 34.3$)$ \\
\hline Repeat operation, $n(\%)$ & $4(44.4)$ & $1(5)$ & $0.01(7.8$ to 68.6$)$ \\
\hline Number of operations, mean \pm SD & $2.2 \pm 1.1$ & $1.2 \pm 1.2$ & $0.07(-1.9$ to 0.06$)$ \\
\hline $\mathrm{HT}, n(\%)$ & $2(22.2)$ & $3(15)$ & $0.64(-19.2$ to 41.2$)$ \\
\hline Smoking, $n(\%)$ & $1(11.1)$ & $1(5)$ & $0.55(-14.6$ to 38.7$)$ \\
\hline Cumulative CTA count, mean (range) & $3.8,(3-6)$ & $2.8,(1-5)$ & $0.04(-1.9$ to -0.04$)$ \\
\hline Cumulative CTDIvol (mGy), mean \pm SD & $44.8 \pm 17.53$ & $26.7 \pm 12.86$ & $0.0042(-29.9$ to -6.2$)$ \\
\hline Cumulative DLP (mGy.cm), mean \pm SD & $1100.78 \pm 686.1$ & $712.9 \pm 316.3$ & $0.04(-765.2$ to -10.6$)$ \\
\hline The excessive lifetime risk for all cancer * & $2005.3 \pm 330.1$ & $1713.5 \pm 226.0$ & $0.009(-506.9$ to -76.7$)$ \\
\hline The excessive lifetime risk for lung cancer & $352.9 \pm 24.8$ & $259.3 \pm 35.8$ & $<0.0001(-120.7$ to -66.5$)$ \\
\hline The baseline future risk for all cancer ** & $25943.9 \pm 6601.4$ & $26219.7 \pm 6257.2$ & $0.91(-4963.1$ to 5514.7$)$ \\
\hline
\end{tabular}

BMI, body mass index; CTA, computed tomography angiography; DLP, dose length product; CTDI $_{\mathrm{vol}}$, computed tomography dose index volume; SD, standard deviation. * The lifetime risk of developing cancer of the ionizing radiation (chances in 100,000) with a $90 \%$ uncertainty range and risk from the time of exposure to the end of the expected lifetime. ${ }^{* *}$ Risk from 2021 to the end of the expected lifetime $p$-value $<0.05$ is considered statistically significant.

Table 3. Summary data for CTA counts, radiation dose, the excessive lifetime risk of all cancer, excessive lifetime risk for lung cancer, the baseline future risk for all cancer, and the total future risk (per 100,000).

\begin{tabular}{cc}
\hline Cumulative CTA Count, Mean (Range) & $\mathbf{1 ~ ( 1 - 6 )}$ \\
\hline Cumulative CTDI vol $(\mathrm{mGy})$, mean $\pm \mathrm{SD}$ & $21.5 \pm 14.68$ \\
\hline Cumulative DLP $\left(\mathrm{mGy}{ }^{*} \mathrm{~cm}\right)$, mean $\pm \mathrm{SD}$ & $682.2 \pm 466.7$ \\
\hline The excessive lifetime risk for all cancer ${ }^{*}$ & $2080.3 \pm 1330.1$ \\
\hline The excessive lifetime risk for lung cancer & $288.4 \pm 214.8$ \\
\hline The baseline future risk for all cancer ${ }^{* *}$ & $26,134.1 \pm 7601.4$ \\
\hline The total future risk for all cancer ${ }^{* *}$ & $27,509.3 \pm 9208.2$ \\
\hline
\end{tabular}

CTA, computed tomography angiography; DLP, dose length product; CTDIvol, computed tomography dose index volume; SD, standard deviation. * The lifetime risk of developing cancer of the ionizing radiation (chances in 100,000) with a $90 \%$ uncertainty range and risk from the time of exposure to the end of the expected lifetime. ** Risk from 2021 to the end of the expected lifetime. 


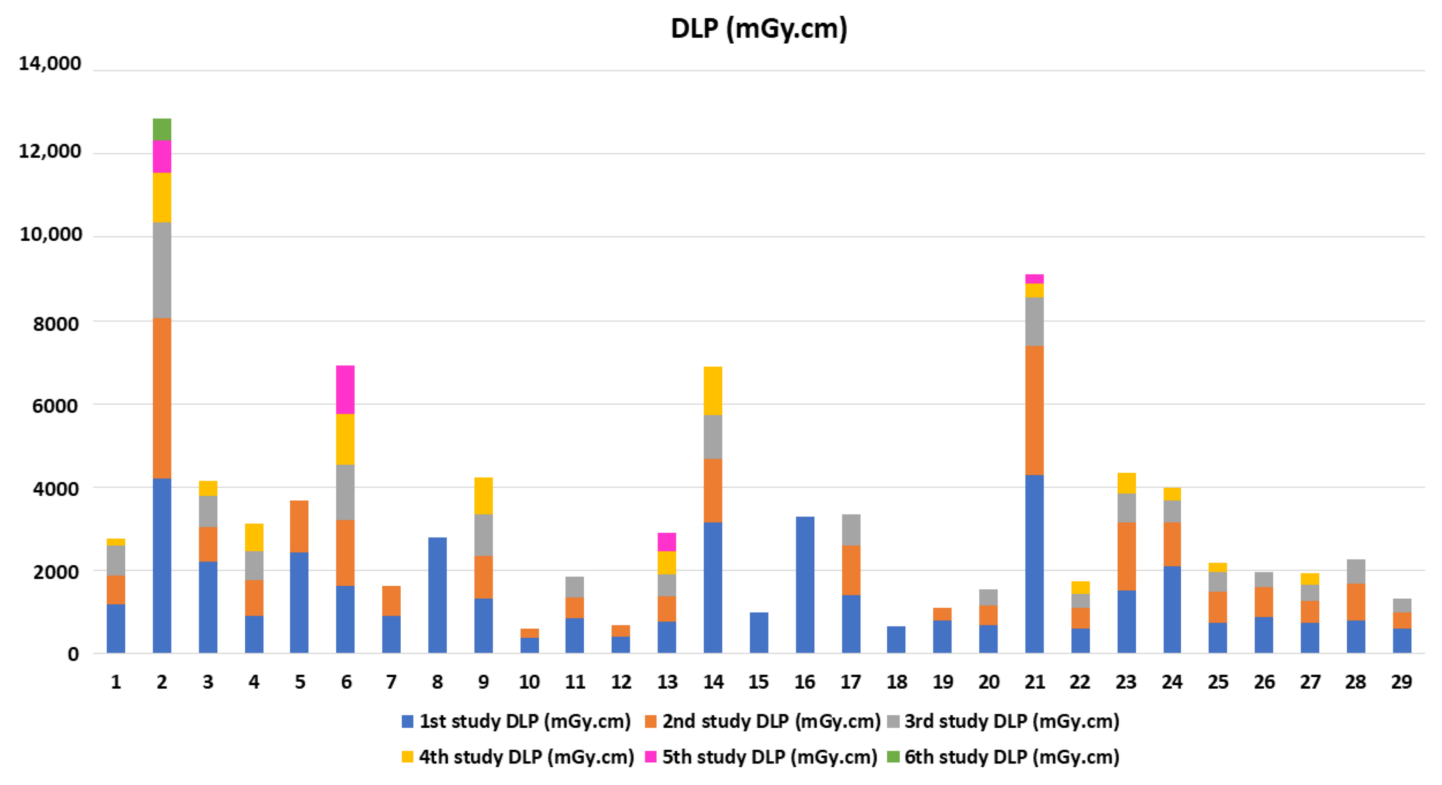

Figure 3. The cumulative dose length product (DLP) of each individual.

\section{CTDI vol (mGy)}

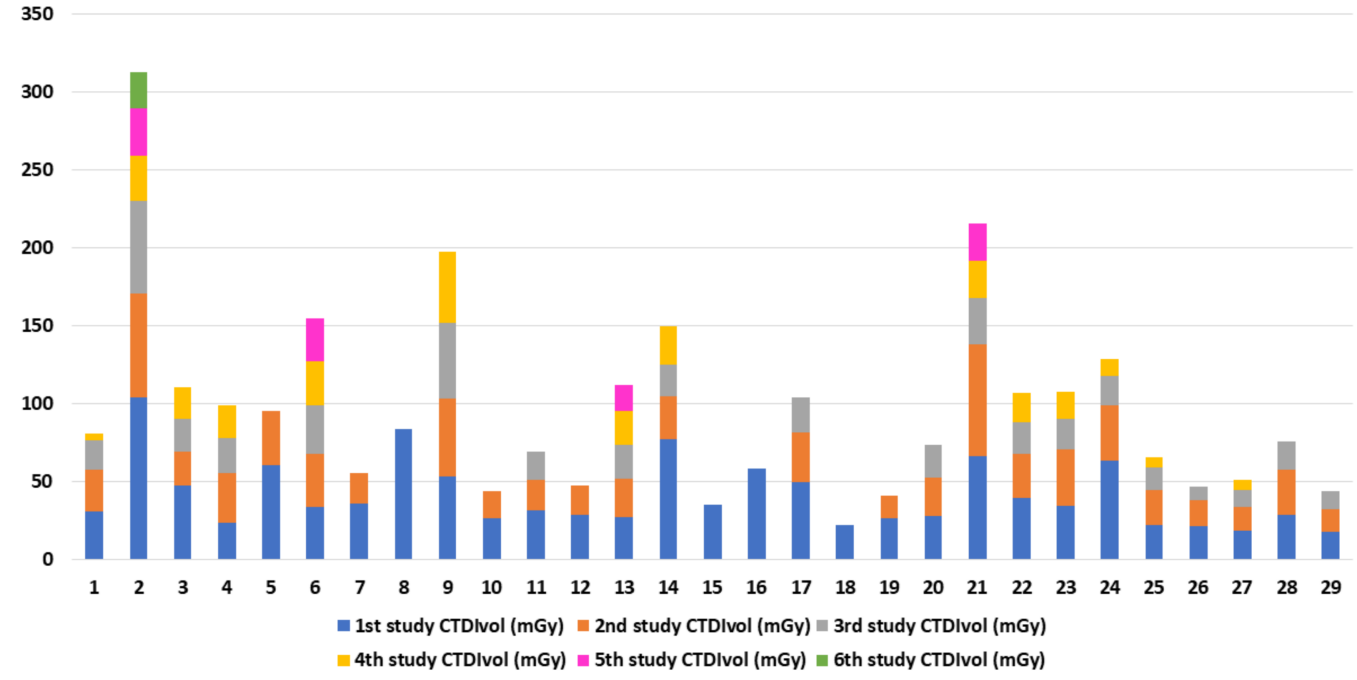

Figure 4. The cumulative computed tomography dose index volume $\left(\mathrm{CTDI}_{\mathrm{vol}}\right)$ for each individual. 
The life time risk of developing cancer with chances in 100,000

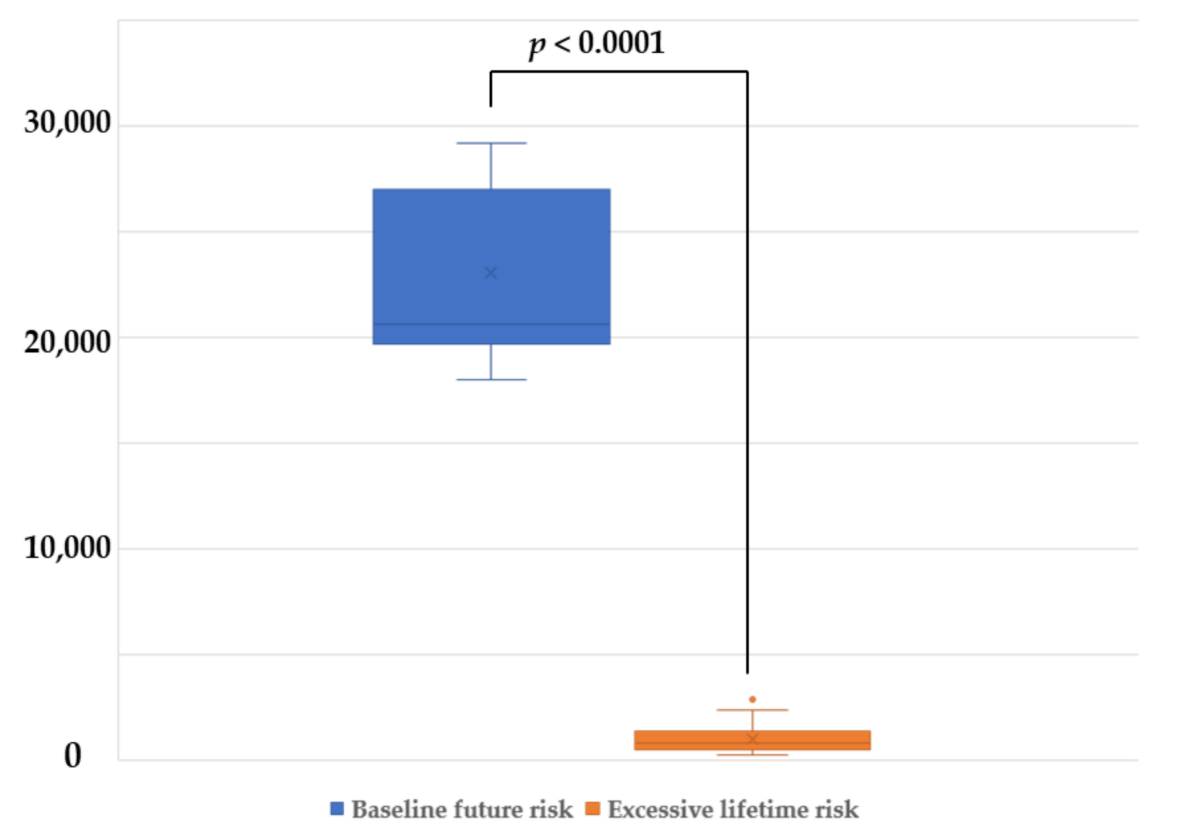

Figure 5. Comparison between the lifetime risk of developing cancer with chances in 100,000 between baseline future risk and the excessive lifetime risk of developing cancer.

\section{Discussion}

Computed tomography angiography (CTA) is more generally available, less expensive, and maybe performed safely in patients with pacemakers and other MRI contraindications. Multidetector CTA allows for faster scanning of the aorta with isotropic voxel data and higher spatial resolution. Aneurysm detection sensitivity, specificity, and accuracy have all increased considerably with modern-generation CT scanners $[8,15,16]$. To our knowledge, our report represents the first analysis of MFS patient radiation dose who underwent CTA in Thailand. It is hoped that this will stimulate interest in the region to benefit patients and staff and create awareness of radiation safety among clinicians and radiologists. In the present study, we demonstrated cumulative radiation dose, and the radiation risk calculator estimates lifetime attributable risk from the time of exposure until the end of the expected lifetime in Marfan syndrome patients who underwent CTA.

The present study demonstrated that the lifetime risk of radiation-induced all cancers $(2080.3 \pm 1330.1$ per 100,000$)$ and lung cancer $(288.4 \pm 214.8$ per 100,000$)$ associated with the CTA surveillance study is significantly lower than the risk of aortic dissection or rupture (1.33\% of MFS with an aortic diameter of 50 to $54 \mathrm{~mm}$ had aortic adverse events and aortic diameter $\geq 50 \mathrm{~mm}$, the danger rose fourfold) [17-21]. Malhotra A. et al. discovered that the primary factors contributing to an excess lifetime risk are obtaining CTA followup at a younger age, more frequent follow-up, a longer surveillance duration, and male gender [22]. This is comparable to the emergency surgery group in the present study, which had significantly higher cumulative CTDIvol, DLP, excess lifetime risk for all cancer, and excessive lifetime risk for lung cancer.

The National Cancer Institute established the RadRAT tool for assessing radiationlinked lifetime risk given a particular exposure history [14]. The risk is determined by sex, achieving age, and exposure age. It summarizes the risk associated with each exposure as well as the overall risk associated with all exposures. The program evaluates the cumulative excessive lifetime risk following exposure since the risk of radiation-related cancer remains increased for at least 50 years. The risk-benefit decision between the cancer risk versus the advantages of surveillance imaging to prevent complications must be taken at the patient 
level. It requires considering the advantages of surveillance imaging in predicting rupture and providing effective, safe treatment, hence reducing morbidity and mortality.

Since the chance of mortality from developing more than one radiation-related cancer because of a single exposure is extremely low for doses below $1 \mathrm{~Gy}$, the lifetime attributable risk and risk of exposure-induced cancer (REIC) are almost similar for the radiation doses per scan evaluated in RadRAT [14,17-20]. The increased use of CTA raises radiation concerns since cumulative CT radiation exposure from several CTA examinations adds progressively to baseline cancer risk. Observational studies to determine CTA-related cancer risks would be impossible to conduct since they would require large studies and long-term follow-up. The increased risk of benign and malignant tumors of the lung and other organs is likely insignificant compared to the chance of aortic dissection or rupture in Marfan syndrome patients, which can cause considerable morbidity and death [6,7,13-16]. The risk of radiation-related cancer has been demonstrated to remain elevated for at least fifty years after exposure to radiation, effectively for the remainder of a person's life. As a result, the cumulative excess lifetime risk, computed as the sum of the agespecific hazards adjusted for the chance of surviving to that age, is a typical summary statistic for reflecting the whole potential detriment of an exposure. The radiation risk calculator calculates lifetime attributable risk from the period of the exposure until the end of the predicted lifetime [12-14]. When assessing the risk of radiation-induced cancer, the variation in radiation doses from each exposure must be taken into account. Patient size, imaging parameters (scan length, tube voltage, and tube current-time product), and scanner technology affect CT effective dose [8,23]. Effective dosages of 1.1-9.4 mSv have been reported for CTA in assessing Marfan syndrome patients [8,23,24]. Radiation doses associated with CTA are reducing incrementally because of advanced technology like dualsource CTA and strategies including iterative reconstruction [8,23-25]. According to the International Commission on Radiological Protection, absorbed doses up to $100 \mathrm{mGy}$ do not cause deterministic radiation effects or clinically relevant functional impairment in any tissue $[17,20]$. Because of the delayed effect of radiation and the extremely low incidence of radiation-induced cancer, determining such risks directly through observational studies would generally need unfeasibly large studies with long-term follow-up to achieve relevant statistical power.

Even though there are promising results, there are some limitations and considerations to keep in mind. Firstly, our research was limited to the general Thai population, with an emphasis on Asians. Certain groups and individuals may be more radiosensitive and risk developing cancer after ionizing radiation. Secondly, since we did not evaluate CTA performed at other hospitals before the patient was referred to our hospital, we possibly underestimated the cumulative effective doses. Furthermore, interventional radiology, nuclear medicine, invasive angiography, and other radiography studies were excluded from the study. Thirdly, due to retrospective study design, we cannot have pharmacological treatment information and the impact of the confounding factors in the recruited patients. Finally, the present study was conducted in the single-centered with a small sample size due to the rarity of the disease in our population. Future prospective study design, the multi-centered, and larger sample size should be performed to address the importance of the present study results.

\section{Conclusions}

We attempted to quantify the risk of radiation-induced cancer from CTA surveillance imaging performed for MFS patients in this study, with all patients receiving a low-risk cumulative radiation dose (less than $1 \mathrm{~Gy}$ ). The excess lifetime risk of radiation-induced cancer associated with the CTA surveillance study $(0.02 \%)$ is significantly lower than the baseline future risk of cancer (26\%) and lower than the risk of aortic dissection or rupture. (1.33\% of MFS with an aortic diameter of 50 to $54 \mathrm{~mm}$ had aortic adverse events, and with aortic diameter $\geq 50 \mathrm{~mm}$, the danger rose fourfold). The risk-benefit decision must be taken at the point of care, and it requires balancing the benefits of surveillance imaging in 
predicting rupture against the benefits of practical, safe treatment, therefore minimizing morbidity and mortality.

Author Contributions: Conceptualization, N.C.; methodology, N.C.; validation, N.C.; formal analysis, N.C.; investigation, N.C.; resources, P.M.; data curation, P.A.; writing—original draft preparation, N.C.; writing-review and editing, N.C.; visualization, P.M.; supervision, N.C. All authors have read and agreed to the published version of the manuscript.

Funding: This research received no external funding.

Institutional Review Board Statement: The study was conducted according to the guidelines of the Declaration of Helsinki and approved by the Institutional Review Board (or Ethics Committee) of Khon Kaen University, Thailand, and was registered under reference number HE641421.

Informed Consent Statement: Patient consent was waived due to retrospective study design.

Data Availability Statement: Not applicable.

Acknowledgments: We wish to thank the patients and families for their cooperation. We also would like to thank cardiology staff at the department of medicine, ophthalmologists, cardiothoracic surgeons, and orthopedic surgeons for their patient care services. The authors thank the Department of Radiology, Surgery, and Faculty of Medicine for their support.

Conflicts of Interest: The authors declare no conflict of interest.

\section{References}

1. Vanem, T.T.; Geiran, O.R.; Krohg-Sørensen, K.; Røe, C.; Paus, B.; Rand-Hendriksen, S. Survival, causes of death, and cardiovascular events in patients with Marfan syndrome. Mol. Genet. Genom. Med. 2018, 6, 1114-1123. [CrossRef]

2. Loeys, B.L.; Dietz, H.C.; Braverman, A.C.; Callewaert, B.L.; De Backer, J.; Devereux, R.B.; Hilhorst-Hofstee, Y.; Jondeau, G.; Faivre, L.; Milewicz, D.M.; et al. The revised Ghent nosology for the Marfan syndrome. J. Med Genet. 2010, 47, 476-485. [CrossRef]

3. Von Kodolitsch, Y.; De Backer, J.; Schüler, H.; Bannas, P.; Behzadi, C.; Bernhardt, A.M.; Hillebrand, M.; Fuisting, B.; Sheikhzadeh, S.; Rybczynski, M.; et al. Perspectives on the revised Ghent criteria for the diagnosis of Marfan syndrome. Appl. Clin. Genet. 2015, 8, 137-155. [CrossRef] [PubMed]

4. Baumgartner, H.; Bonhoeffer, P.; De Groot, N.M.; Haan, F.; Deanfield, J.E.; Galie, N.; Gatzoulis, M.A.; Beaerwolf, C.G.; Kaemmerer, H.; Kilner, P.; et al. Task Force on the Management of Grown-up Congenital Heart Disease of the European Society of Cardiology (ESC); Association for European Paediatric Cardiology(AEPC); ESC Committee for Practice Guidelines(CPG). ESC guidelines for the management of grown-up congenital heart disease (new version 2010). Eur. Heart J. 2010, 31, 2295-2915.

5. Jost, C.; Greutmann, M.; Connolly, H.; Weber, R.; Rohrbach, M.; Oxenius, A.; Kretschmar, O.; Luscher, T.; Matyas, G. Medical Treatment of Aortic Aneurysms in Marfan Syndrome and other Heritable Conditions. Curr. Cardiol. Rev. 2014, 10, 161-171. [CrossRef]

6. Song, H.K.; Kindem, M.; Bavaria, J.E.; Dietz, H.C.; Milewicz, D.M.; Devereux, R.B.; Eagle, K.A.; Maslen, C.L.; Kroner, B.L.; Pyeritz, R.E.; et al. Genetically Triggered Thoracic Aortic Aneurysms and Cardiovascular Conditions Consortium. Long-term implications of emergency versus elective proximal aortic surgery in patients with Marfan syndrome in the Genetically Triggered Thoracic Aortic Aneurysms and Cardiovascular Conditions Consortium Registry. J. Thorac. Cardiovasc. Surg. 2012, 143, 282-286. [CrossRef] [PubMed]

7. Pepe, G.; Giusti, B.; Sticchi, E.; Abbate, R.; Gensini, G.F.; Nistri, S. Marfan syndrome: Current perspectives. Appl. Clin. Genet. 2016, 9, 55-65. [CrossRef] [PubMed]

8. Freyhardt, P.; Solowjowa, N.; Böning, G.; Kahn, J.; Aufmesser, B.; Haage, P.; Streitparth, F. CT-angiography of the aorta in patients with Marfan disease -High-pitch MDCT at different levels of tube voltage combined with Sinogram Affirmed Iterative Re-construction. Clin. Imaging 2018, 51, 123-132. [CrossRef] [PubMed]

9. Erbel, R.; Aboyans, V.; Boileau, C.; Bossone, E.; Bartolomeo, R.D.; Eggebrecht, H.; Evangelista, A.; Falk, V.; Frank, H.; Gaemperli, O.; et al. ESC guidelines on the diagnosis and treatment of aortic diseases: Document covering acute and chronic aortic diseases of the thoracic and abdominal aorta of the adult. The task force for the diagnosis and treatment of aortic diseases of the European Society of Cardiology (ESC). Eur. Heart J. 2014, 35, 2873-2926.

10. Stout, K.K.; Daniels, C.J.; Aboulhosn, J.A.; Bozkurt, B.; Broberg, C.S.; Colman, J.M.; Crumb, S.R.; Dearani, J.A.; Fuller, S.; Gurvitz, M.; et al. 2018 AHA/ACC Guideline for the Management of Adults with Congenital Heart Disease: Executive Summary: A Report of the American College of Cardiology/American Heart Association Task Force on Clinical Practice Guidelines. Circulation 2019, 139, e637-e697. [CrossRef]

11. Shen, Y.; Sun, Z.; Zixu, Y.; Li, Y.; Zhang, N.; Yanguang, S.; Fan, Z. High-Pitch, Low-Voltage and Low-Iodine-Concentration CT Angiography of Aorta: Assessment of Image Quality and Radiation Dose with Iterative Reconstruction. PLoS ONE 2015, 10, e0117469. [CrossRef] 
12. Griffey, R.T.; Sodickson, A. Cumulative radiation exposure and cancer risk estimates in emergency department patients undergoing repeat or multiple CT. AJR Am. J. Roentgenol. 2009, 192, 887-892. [CrossRef] [PubMed]

13. Sodickson, A.; Baeyens, P.F.; Andriole, K.P.; Prevedello, L.; Nawfel, R.D.; Hanson, R.; Khorasani, R. Recurrent CT, Cumulative Radiation Exposure, and Associated Radiation-induced Cancer Risks from CT of Adults. Radiology 2009, 251, 175-184. [CrossRef]

14. De Gonzalez, A.B.; Apostoaei, A.I.; Veiga, L.H.; Rajaraman, P.; Thomas, B.A.; Hoffman, F.O.; Gilbert, E.; Land, E.C. RadRAT: A radiation risk assessment tool for lifetime cancer risk projection. J. Radiol. Prot. 2012, 32, 205-222. [CrossRef]

15. Milewicz, D.M.; Braverman, A.C.; De Backer, J.; Morris, S.A.; Boileau, C.; Maumenee, I.H.; Jondeau, G.; Evangelista, A.; Pyeritz, R.E. Marfan syndrome. Nat. Rev. Dis. Prim. 2021, 7, 1-24. [CrossRef] [PubMed]

16. Baumgartner, H.; Backer, J.; Babu-Narayan, S.V.; Budts, W.; Chessa, M.; Diller, G.P.; Lung, B.; Kluin, J.; Lang, I.M.; Meijboom, F.; et al. 2020 ESC Guidelines for the management of adult congenital heart disease: The Task Force for the management of adult congenital heart disease of the European Society of Cardiology (ESC). Eur. Heart J. 2020, 42, 563-645. [CrossRef]

17. Wrixon, A.D. New ICRP recommendations. J. Radiol. Prot. 2008, 28, 161-168. [CrossRef] [PubMed]

18. Ghetti, C.; Ortenzia, O.; Maddalo, M.; Altabella, L.; Sverzellati, N. Dosimetric and radiation cancer risk evaluation of high resolution thorax CT during COVID-19 outbreak. Phys. Med. 2020, 80, 119-124. [CrossRef]

19. Braganza, M.Z.; Kitahara, C.M.; De González, A.B.; Inskip, P.D.; Johnson, K.J.; Rajaraman, P. Ionizing radiation and the risk of brain and central nervous system tumors: A systematic review. Neuro-Oncol. 2012, 14, 1316-1324. [CrossRef] [PubMed]

20. O'Connor, M.K. Risk of low-dose radiation and the BEIR VII report: A critical review of what it does and doesn't say. Phys. Med. 2017, 43, 153-158. [CrossRef]

21. Jondeau, G.; Detaint, D.; Tubach, F.; Arnoult, F.; Milleron, O.; Raoux, F.; Delorme, G.; Mimoun, L.; Krapf, L.; Hamroun, D.; et al. Aortic event rate in the Marfan population: A cohort study. Circulation 2012, 125, 226-232. [CrossRef]

22. Malhotra, A.; Wu, X.; Chugh, A.; Mustafa, A.; Matouk, C.C.; Gandhi, D.; Sanelli, P. Risk of Radiation-induced cancer from computed tomography angiography use in imaging surveillance for unruptured cerebral aneurysms. Stroke 2019, 50, 76-82. [CrossRef] [PubMed]

23. Boos, J.; Aissa, J.; Lanzman, R.S.; Heusch, P.; Schimmöller, L.; Schleich, C.; Thomas, C.; Antoch, G.; Kröpil, P. CT angiography of the aorta using $80 \mathrm{kVp}$ in combination with sinogram-affirmed iterative reconstruction and automated tube current modulation: Effects on image quality and radiation dose. J. Med. Imaging Radiat. Oncol. 2016, 60, 187-193. [CrossRef]

24. Örgel, A.; Bier, G.; Hennersdorf, F.; Richter, H.; Ernemann, U.; Hauser, T.K. Image Quality of CT Angiography of Supra-Aortic Arteries: Comparison Between Advanced Modelled Iterative Reconstruction (ADMIRE), Sinogram Affirmed Iterative Reconstruction (SAFIRE) and Filtered Back Projection (FBP) in One Patients' Group. Clin. Neuroradiol. 2020, 30, 101-107. [CrossRef] [PubMed]

25. Zizka, J.; Ryška, P.; Stepanovska, J.; Poulova, Z.; Klzo, L.; Grepl, J.; Cermakova, E. Iterative reconstruction of pulmonary MDCT angiography: Effects on image quality, effective dose and estimated organ dose to the breast. Biomed. Pap. 2014, 158, $259-264$. [CrossRef] [PubMed] 